\title{
Miniature Garden Sprinkler
}

\author{
Fenglan Wang \\ School of Mechanical Engineering, Shenyang \\ University \\ Shenyang Liaoning, China \\ e-mail: flwang1965@sina.com \\ Sihan Yang \\ Shenyang University \\ City, Shenyang Liaoning, China \\ e-mail:name@xyz.com
}

\begin{abstract}
In this paper, the author brings up an innovative design of garden sprinkler that makes up the defect of a large-sized sprinkler, which cannot be used in smaller gardens. A miniature sprinkler has a remote control system and a height-and-pressure adjustable sprayer, with a small size that can easily fit in gardens in communities, villa areas and urban squares. This design is invented to release the pressure of gardeners, to save time and energy, and to bring convenience to all citizens.
\end{abstract}

Keywords-Garden Irritation, Remote Control, Sprinkler, Portable, Time-and-Energy Saving.

\section{INTRODUCTION}

With enhancing life quality in modern society, more buildings are being constructed since the existing ones are incapable of meeting all human needs. Meanwhile, people start to pay more attention to spiritual demands and to protect the environment; thus, urban gardens come to existence. There are all kinds of gardens, such as large gardens, small parks and greenbelts. Generally, large-sized parks and greenbelts are irritated using common sprinklers. When it comes to irritation of smaller gardens and greenbelts, however, human labor would be too expensive while common sprinklers are too large. The existing sprinkler is also known as multi-functional green sprinkler. For urban roads, large factory, troops, gardens and other unit to clean the road, health, dust, water, pesticides, etc., to beautify the environment. At the same time can be used for temporary emergency fire sprinkler, sprinkler each are equipped with fire special interface. By the engine drive gearbox, gearbox of apply force to drive the pump and the installed on main power sprinkle water pump, the liquid inside the tank through the spraying pipe network. Selfpriming height: $7 \mathrm{~m}$ or less, sprinkler width: p $20 \mathrm{~m}$, and maximum range: $28 \mathrm{~m}$ or higher; The adjustable pillars, range $28 \mathrm{~m}$ or higher; Also can be adjusted into fog, a range of $5 \mathrm{~m}$ or more. With duck shape nozzle spray after shower, before or round head blunt mouth, cylindrical open sprinkler nozzle or shower nozzle, mounted behind the back of the one work platform, equipped with water cannon. Rear can put eight nozzle (optional) spray are commonly used to hose down the streets. This sprinkler doesn't into smaller in small gardens and urban green belts.

\author{
Bo Gao \\ Shenyang University \\ Shenyang Liaoning, China \\ e-mail: 497601981@qq.com
}

To solve the problem, we have invented a remotecontrollable miniature garden sprinkler with simple structure and practical functions.

\section{THE APPLICATION PRINCIPLE OF MiniATURE GARDEN SPRINKLER}

This is how a miniature garden sprinkler works: the battery car is loaded with a water tank and can be manually controlled by a remote controller. On the car, there is a scalable spray with adjustable water pressure, which is capable of irritating trees of different heights. On the chassis, there are rolling nozzles for the irritation of lawns. Both speed of the car and spray pressure adjustable.Piping system: the piping, four three-way ball valve, through ball valve, filter, outlet (forward and sprinkle, lateral jet; high side shower; after working platform, with green sprinkler anti-aircraft gun). Operating system: mainly by the engine drive gearbox, transmission of apply force to drive the pump and the installed on power sprinkle water pump, the liquid inside the tank through the spraying pipe network. Job scope: selfpriming height: $7 \mathrm{~m}$ or more, sprinkler width: p $14 \mathrm{~m}$, maximum range: $28 \mathrm{~m}$ or higher; The adjustable pillars, range $28 \mathrm{~m}$ or higher; Also can be adjusted into fog, a range of $5 \mathrm{~m}$ or more. Sprinkle water pump: equipped with sprinkler spray, green car high-power special sprinkling water pump, fire joint, with their valves, with the function of self-priming. Configuration options, can be mounted for spraying plate, pump, tank anticorrosion and multidimensional in and out of the water fittings, solenoid valve, pneumatic valve and other advanced facilities, to meet different user requirements. After spraying (1) the fourway valve handle to parallel to the ground, and opened to spray ball valves (forward, after the spill, side spray, flower is aspersed), and then start the engine, will hang into the gear transmission, will take power switch back the shift force, then the separation of the clutch, the pump running, began to water; (2) after the vats of water sprinkling, driving should be timely to take power controller forward the unsymmetry, sprinkle water pump stop running. 


\section{PROJECT DETERMINATION AND DESCRIPTION}

As is shown on Graph 1, on the chassis, there are a water tank, a remote control box, an electrical machine and an actuating device. On the upper part of the graph is a drainage pipe with a hydraulic system, through which the water sprays from the nozzles. The base of the car is loaded with an electrical machine and an actuating system. The remote controller can be used to adjust water pressure and intensity. The rotary nozzles are able to cover every direction.

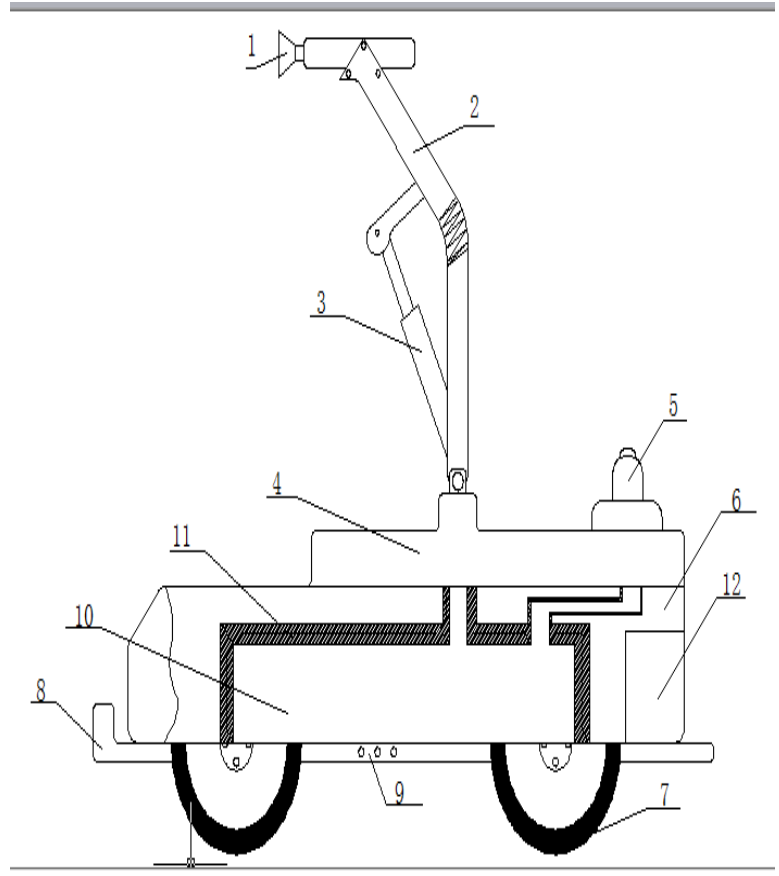

Figure 1. General Structure

1-Upper Nozzle 2-Main Pole 3-Scalable Hydraulic Shaft 4-Top Cover 5Water Entrance 6-Body 7-Wheel 8-Chassis 9-Lower Nozzle 10-Water Tank 11-Water Pipe 12-Circuit Control Box

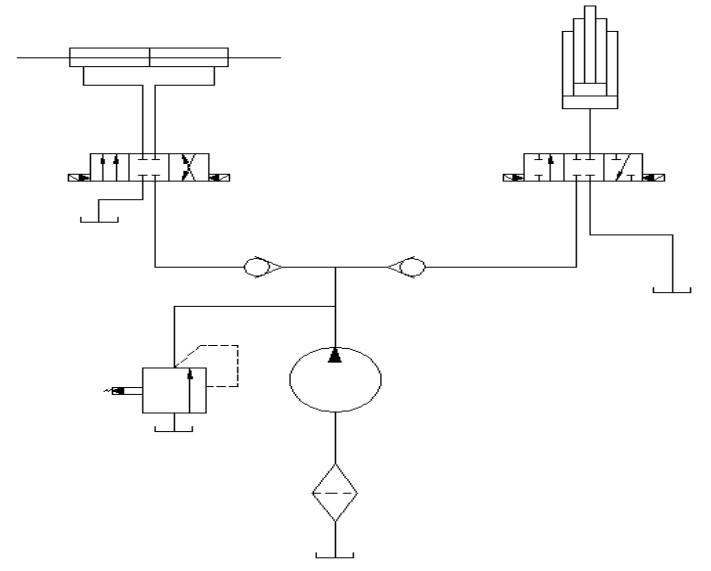

Figure 2. Hydraulic system diagram

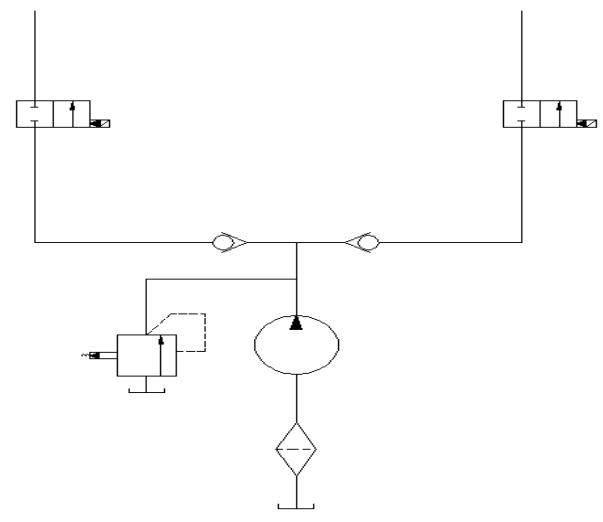

Figure 3. The water system diagram

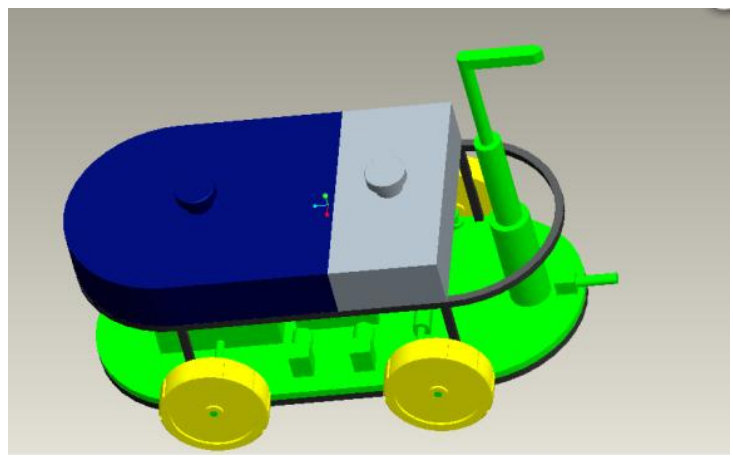

Figure 4. 3D model

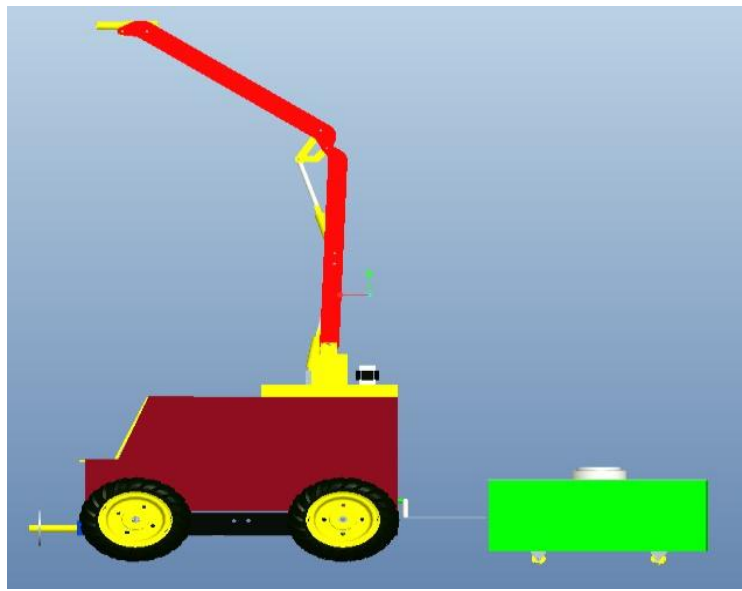

Figure 5. The whole 


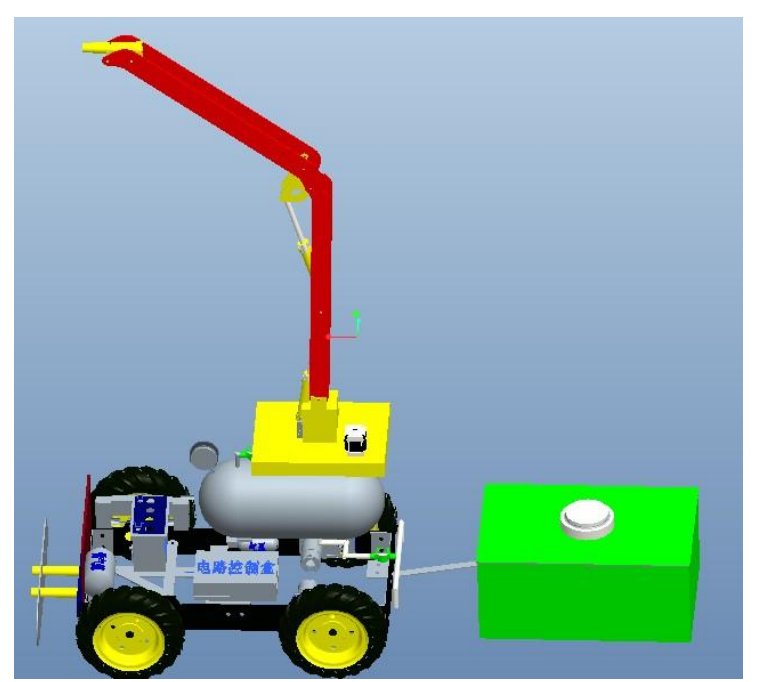

Figure 6. Internal

\section{CONCLUSIONS}

$\mathrm{B}(1)$ This design reaches the goal of irritating small gardens without labor force by reducing the size of common sprinklers;

(2)It is manually remote-controllable;

(3) It has a simple structure similar to a toy vehicle, which brings great convenience.

The science in this design: The miniature garden sprinkler irritates smaller gardens by a remote control system. The car is led by an electrical machine through a transmission device and controlled remotely by human.

\section{APPLICATIONS AND SIGNIFICANCE}

(1)The common sprinklers on the market, which are only suitable for greenbelts, fail to cover smaller gardens among urban parks because of their size and the narrow paths. This product is invented to solve such problems, and, therefore, has a promising future;

(2)It is a new miniature garden sprinkler with a simple structure and practical functions;

(3) It is easy to handle and save time and energy of the gardeners.

\section{REFERENCES}

[1] Gao Zhi, Liu Ying. Innovative Design for Machinary. Qinghua University Press. 2009.

[2] Yang Jiajun. Innovative Design for Mechanical System. Huazhong University of Science and Technology Press. January, 2000.

[3] Zhang Chunlin and others. Innovative Design for Machinary. Beijing : China Machine Press. 2007.

[4] Li Bomin, Dr. Bo. The modern grinding technology [M]. Beijing: mechanical industry press, 2003.

[5] Jun-sheng zhang. Metal cutting machine tools and CNC machine [M]. Beijing: mechanical industry press, 1994.

[6] Bing-heng lu. "mechanical manufacturing technology foundation" [M]. Beijing: mechanical industry press in 2007/12

[7] He Dingyuan Gu Hongshu. Mechanism of the crust breaker work [J]. Mechanical manufacturing 2013/12

[8] Wang Yu. Cylinder processing technology analysis [J]. Journal of hangyang technology 1995/04. 